\title{
Mcm10 and the MCM2-7 complex interact to initiate DNA synthesis and to release replication factors from origins
}

\author{
Lisa Homesley, ${ }^{1,4}$ Ming Lei, ${ }^{2,4}$ Yasuo Kawasaki, ${ }^{3}$ Sara Sawyer, Tim Christensen, and Bik K. Tye ${ }^{5}$ \\ Department of Molecular Biology and Genetics, Cornell University, Ithaca, New York 14853-2703 USA
}

\begin{abstract}
MCM2-7, a complex of six subunits, is an essential component of the prereplication chromatin that is assembled at Saccharomyces cerevisiae replication origins during $G_{1}$ phase. It is also believed to be the processive helicase at growing forks. To elucidate the action of MCM2-7 during the transition from initiation to elongation replication, we have focused our studies on $\mathrm{Mcm} 10$, a replication initiation protein that physically interacts with members of the MCM2-7 complex. We show that Mcm10 is a chromatin-associated protein that mediates the association of the MCM2-7 complex with replication origins. Furthermore, diminished interaction between $\mathrm{Mcm} 10$ and $M \mathrm{~cm}$, a subunit of the MCM2-7 complex, by a mutation in either Mcm10 or Mcm7 inhibits replication initiation. Surprisingly, a double mutant containing both the mcm10-1 and mcm7-1 (cdc47-1) alleles restores interaction between $\mathrm{Mcm} 10$ and $\mathrm{Mcm}$ 7 and corrects all of the defects exhibited by each of the single mutants, including the stalling of replication forks at replication origins typically seen in mcm10-1 cells. This mutual compensation of defects between two independently isolated mutations is allele specific. These results suggest that $M \mathrm{~cm} 10$, like $M \mathrm{~cm} 7$, is a critical component of the prereplication chromatin and that interaction between $\mathrm{Mcm} 10$ and $\mathrm{Mcm} 7$ is required for proper replication initiation and prompt release of origin-bound factors.
\end{abstract}

[Key Words: MCM2-7 complex; Mcm10; Cdc45; DNA synthesis; replication initiation]

Received October 14, 1999; revised version accepted March 7, 2000.

Fidelity of genome duplication is essential for the procreation of life. Eukaryote genomes are organized into multiple chromosomes and initiation of DNA synthesis starts from not one but numerous sites on each chromosome. To ensure fidelity, these multiple initiation events must be coordinated such that on completion, the entire genome is duplicated exactly once. The strategy for this regulated process is beginning to emerge from the collective works of a number of laboratories. Key to this strategy is the periodic recruitment and discharge of a hexameric complex, MCM2-7, to forge a cycle of activity and inactivity at replication origins (Diffley 1996; Tye 1999). Although the concept of the temporal separation of an active and an inactive chromatin state at replication origins is relatively simple, the number of protein factors involved in this process suggests a com-

Present addresses: ${ }^{1342}$ Sinsheimer Labs, University of California, Santa Cruz, California 95064 USA; $^{2}$ Department of Microbiology and Molecular Genetics, Medical College of Wisconsin, Milwaukee, Wisconsin 53226 USA; ${ }^{3}$ Research Institute for Microbial Diseases, Osaka University, Suita, Osaka 565, Japan.

${ }^{4}$ These authors contributed equally to this work.

${ }^{5}$ Corresponding author.

E-MAIL bt16@cornell.edu; FAX (607) 255-2428. plex and intricate scheme. The origin recognition complex (ORC) is a complex of six subunits that constitutively binds origin DNA and "bookmarks" the sequences (Bell and Stillman 1992). Recruitment of the MCM complex to replication origins is facilitated by the short-lived replication initiation factor Cdc6 (Coleman et al. 1996; Donovan et al. 1997). At the cue of the cell cycle-dependent kinases Cdc7-Dbf4 and Cdc28-Clb, a sequence of events involving participation of Cdc45 activates the transition of replication initiation to replication elongation (Lei et al. 1997; Zou et al. 1997; Zou and Stillman 1998). During this transitional process, the inactive MCM2-7 complex is believed to transform into an active helicase that first melts the origin DNA and then processively unwinds the growing fork (Aparicio et al. 1997; Kelman et al. 1999; You et al. 1999; Chong et al. 2000). Replication origins that are no longer occupied by the MCM complex are inactive and this period of inactivity extends into the next $G_{1}$ phase when a new cycle of activity begins again with the recruitment of the MCM2-7 complex.

Although there is strong evidence that the MCM2-7 complex plays a key role both in initiation and in elongation replication, the mechanistic detail of the different 
roles that it plays is unknown. In particular, the relationship between MCM2-7 and the accessory factors that facilitate its activities requires further investigation. For example, the recruitment of the MCM2-7 complex to replication origins is dependent on ORC (Santocanale and Diffley 1996) and Cdc6 (Liang and Stillman 1997; Tanaka et al. 1997), yet there is little evidence for physical interactions between MCM2-7 with either of these proteins. On the other hand, the MCM2-7 complex is known to interact with two replication initiation factors, Cdc45 (Hopwood and Dalton 1996) and Mcm10 (Merchant et al. 1997). However, the context and the functional significance of these interactions have yet to be explored. To understand better the roles of the MCM2-7 complex in DNA replication, we focus our studies on Mcm10 and its functional relationship with subunits of the MCM2-7 complex.

Originally, Mcm10 was identified in the same screen in which several members of the MCM2-7 family were first isolated (Maine et al. 1984), although Mcm 10 shows no structural similarity to members of this family. Physical interactions between Mcm 10 and several members of the MCM2-7 family in a two-hybrid assay suggest a functional relationship between these proteins through contacts (Merchant et al. 1997). Phenotypes of the $\mathrm{mcm} 10$ mutants suggest that Mcm10 may have multiple roles in regulating DNA replication. First, the mcm10-1 mutant is defective in the initiation of DNA synthesis. This defect is illustrated by the instability of minichromosomes even at the permissive temperature of $30^{\circ} \mathrm{C}$, and by the reduced frequency of replication initiation in two-dimensional gel analysis. Second, a pausing phenotype shown by two-dimensional DNA gel analysis indicates stalling of the replication machinery as origin regions are passively replicated. This accumulation of paused replication forks suggests a second role for Mcm10, perhaps in the removal of some tightly bound protein factors from the origin that are blocking the replication machinery, or perhaps in the elongation step itself.

In this paper we discuss new evidence for the roles of Mcm10 in the multistep replication initiation process. First, we show that Mcm10 is a chromatin-associated protein that is also localized at replication origins. Removal of Mcm10 from chromatin results in the dissociation of Mcm2 from chromatin. The suggestion that Mcm10 mediates the association of the MCM2-7 complex with replication origins is supported by the genetic interaction of $\mathrm{Mcm} 10$ with Mcm7, a subunit of the MCM2-7 complex. Two independently isolated mutants, $m c m 10-1$ and $m c m 7-1$, were studied. Individual mutants of Mcm10 or Mcm7 are defective in DNA replication and show diminished interactions between the two proteins. However, we find that the combined effects of lesions in both $\mathrm{Mcm} 7$ and $\mathrm{Mcm} 10$ result in the mutual suppression of all defects exhibited by the individual mutants. We show evidence that the mutual suppression is due to enhanced physical interaction between the mutant Mcm10-1 and Mcm7-1 proteins. The necessity of physical contact between the Mcm10 and Mcm7 proteins for their functions supports the notion that Mcm10 is an integral part of the prereplication chromatin and may play a role in the subsequent release of the MCM2-7 complex from replication origins during replication initiation.

\section{Results}

Elongation forks pause at functional replication origins in a mcm10 mutant

Lesions in Mcm10 not only reduce significantly the frequency of initiation events at replication origins but also induce pausing of elongation forks near these sites (Fig. 1 , cf. A and B). The diagram in Figure $1 \mathrm{~B}$ depicts the accumulation of two species of replication intermediates that result from the pausing of elongation forks from opposite directions at a single site at or near a replication origin typically seen in a mcm10 mutant. The interaction between Mcm10 and subunits of MCM2-7 suggests that the pausing of elongation forks in the mcm10-1 mutant may be related directly to the chromatin structure at replication origins. To investigate this possibility, we introduced mutations into the ORI1 locus and examined the effects of these mutations on the mcm10-1 mutant phenotypes (Fig. 1C). Linker substitution analysis by Marahrens and Stillman (1992) identified several functionally important sequence modules termed A, B1, B2, and $\mathrm{B} 3$ elements in ORI1. The origin activity requires the integrity of the A element and at least two of the

\section{A ORI1 in MCM10 B ORII in mem10-1}
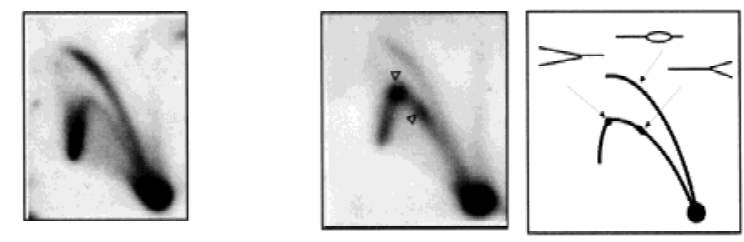

\section{C ori1 in mcm10-1}

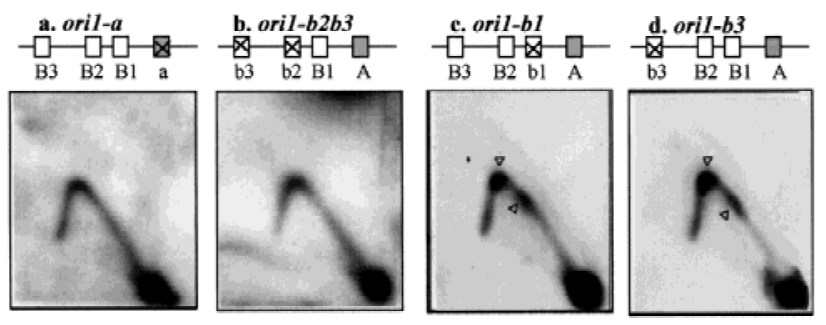

Figure 1. Two-dimensional DNA gel analysis of replicative intermediates in the ORI1 region in the mcm10-1 mutant. $(A)$ ORI1 in a wild-type strain. (B) ORI1 in the mcm10-1 mutant strain. The cartoon is an interpretation of the result showing that the intense spots are due to accumulations of specific species of replicative intermediates. $(C)$ The ori1 alleles in the mcm10-1 mutants: $(a)$ ori1- $a$; $(b)$ ori1-b2b3; $(c)$ ori1-b1; $(d)$ ori1$b 3$. Pause signals are indicated by open triangles. All ori1 alleles were constructed in isogenic mcm10-1 background. 
three B elements. Mutations in any one of the three B elements compromise but do not abolish origin activity. We constructed isogenic mcm10-1 strains with previously described linker-substitution mutations in A, B1, $\mathrm{B} 2+\mathrm{B} 3$, or B3 elements of ORI1 (Marahrens and Stillman 1992).

Effects of these mutations on mom10-1 mutant phenotypes were then examined by two-dimensional DNA gel analysis (Brewer and Fangman 1987). Two intense spots or "pause signals" (open triangles) on the $\mathrm{Y}$ arc result from replication intermediates generated by elongation forks from opposite directions pausing at ORI1 (Fig. 1B). When a mutation that abolishes origin activity was introduced into the A element of ORI1, this locus (ori1-a) was no longer functional as a replication origin as indicated by the absence of an initiation bubble (Fig. 1C, a). Also missing in this ori1-a strain were the pause signals on the $\mathrm{Y}$ arc (Fig. 1C, a). When mutations that abolish origin activity were introduced into both B2 and B3 elements of ORI1 (ori1-b2b3), phenotypes similar to those in the ori1-a strain were observed: no initiation bubble and no pause signals on the $\mathrm{Y}$ arc (Fig. 1C, b). These results suggest that pausing of elongation forks at replication origins requires the integrity of cis-acting elements that are essential for the assembly of prereplication complex (pre-RC) at replication origins.

Mutations in B1 or B3 elements, which impair but do not abrogate origin activity (Marahrens and Stillman 1992), were also introduced into ORI1 in the mcm10-1 strain. In these mutant strains (ori1-b1 and ori1-b3), the intensity of the bubble arcs was detectable but considerably reduced, compared to ORI1 (Fig. 1B) in the same mcm10-1 background, consistent with defects that compromise rather than abolish replication initiation (Fig. $1 \mathrm{C}, \mathrm{c}, \mathrm{d})$. However, pausing of elongation forks was still observed in the $\mathrm{Y}$ arc. These results suggest that replication origins that are compromised in initiation efficiency yet competent to initiate DNA synthesis can also impede the migration of elongation forks in the mcm10-1 mutant. The requirement for a competent origin to induce fork pausing in the $\mathrm{mcm} 10$ mutant suggests an intimate relationship between $\mathrm{Mcm} 10$ and the chromatin structure at the origin.

\section{All cellular Mcm10 proteins are constitutively associated with chromatin}

To gain insights into the functions of Mcm10, we examined the subcellular location of the protein. Whole cell extracts from $\mathrm{G}_{1}-$, S-, or M-phase cells were fractionated into a soluble fraction that includes both cytosol and nucleosol, and a chromatin-enriched pellet fraction (Donovan et al. 1997; Liang and Stillman 1997). The distribution of Mcm10 in these fractions was examined by immunoblot analysis (Fig. 2A). Mcm10 was not detected in the soluble fractions and was found only in the pellets or chromatin fractions of cells at $G_{1}, S$, and $M$ phases of the cell cycle (Fig. 2A, top). In contrast, actin, which is found only in the cytoplasm, was detected only in the soluble fraction (Fig. 2A, middle). The subcellular distri-

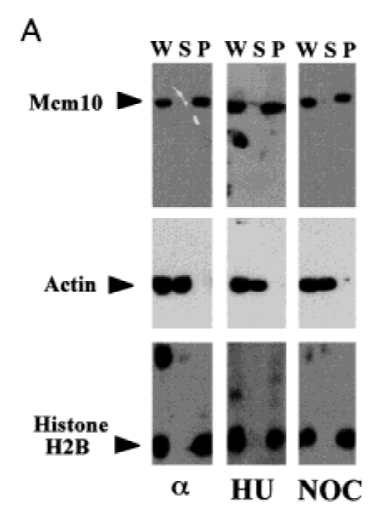

B
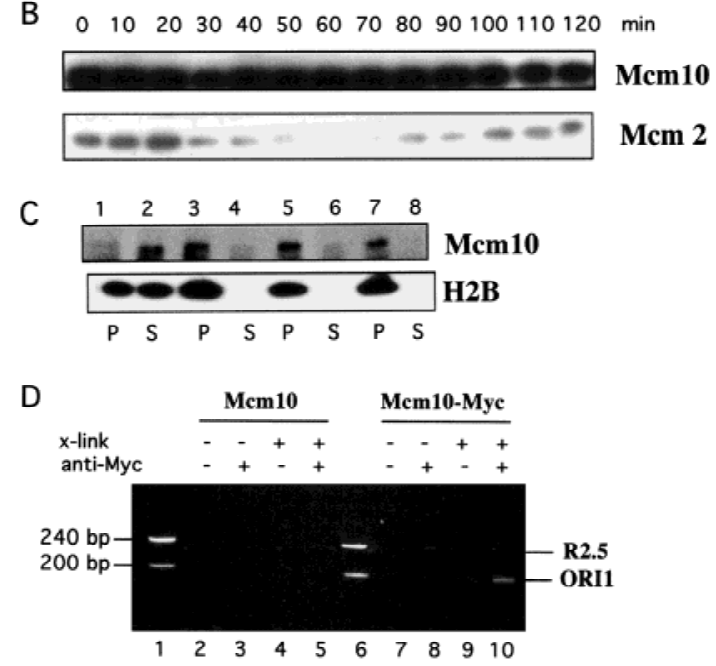

Figure 2. Mcm10 is totally and constitutively bound to chromatin. (A) Western blot analysis of proteins in whole cell extracts $(\mathrm{W})$, soluble fractions $(\mathrm{S})$, and chromatin pellets $(\mathrm{P})$ from cells arrested at either $\mathrm{G}_{1}, \mathrm{~S}$, or $\mathrm{M}$ phases. (Top) Mcm10; (middle) actin; (bottom) histone H2B. (B) Association of Mcm10 and $\mathrm{Mcm} 2$ with chromatin during the time course of one cell cycle. Cells were harvested at 10-min intervals after being released from $\alpha$ factor synchronization. The chromatin pellet of each sample was analyzed in SDS-PAGE and immunoblots were probed with anti-Mcm10 (top) and anti-Mcm2 (bottom) antibodies. (C) Association of Mcm10 with chromatin is DNA dependent. Whole cell extracts were treated at $37^{\circ} \mathrm{C}$ for 10

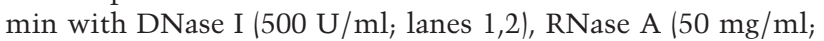
lanes 3,4), NP-40 (2\%; lanes 5,6), or lysis buffer (lanes 7,8), then fractionated into soluble $(\mathrm{S})$ and pellet $(\mathrm{P})$ fractions by centrifugation. Proteins in the pellets (lanes $1,3,5,7)$ and soluble fractions (lanes 2,4,6,8) were separated by SDS-PAGE. Immunoblots were probed with anti-Mcm 10 (top), and anti-histone H2B (bottom) antibodies. Chromatin fractionation was performed essentially as described (Yan et al. 1991; Liang et al. 1995; Donovan et al. 1997) except that a low speed (4000 rpm) centrifugation was performed after the cells were lysed to remove unbroken cells. The yeast strain used in $A, B$, and $C$ is W303bar1. (D) $\mathrm{Mcm} 10$ is localized to ORI1 by in vivo cross-linking. PCR products from crude extracts of Mcm10 (lane 1) and Mcm10-Myc strain (lane 6) as well as immunoprecipitates from the Mcm10 (lanes 2-5) and Mcm10-Myc strain (lanes 7-10) were analyzed on PAG. Samples treated with formaldehyde (lanes $4,5,9,10$ ), or anti-Myc antibodies (lanes 2,3,7,8) are indicated. R2.5 is a 240bp DNA fragment located $2.5 \mathrm{~kb}$ from ORI1. 
bution of Mcm10 was similar to that of histone $\mathrm{H} 2 \mathrm{~B}$ (Fig. 2A, bottom), suggesting that $\mathrm{Mcm} 10$, like $\mathrm{H} 2 \mathrm{~B}$, is constitutively chromatin bound. To verify whether Mcm10 is indeed constitutively chromatin bound throughout the cell cycle, the association of $\mathrm{Mcm} 10$ with chromatin was examined in a time course experiment (Fig. 2B). Yeast cells were first synchronized at $\mathrm{G}_{1}$ phase with $\alpha$ factor and then released to fresh medium. Aliquots of cells were harvested at 10-min intervals until the completion of one cell cycle. Chromatin fractions were prepared from these cells and analyzed for the presence of Mcm2 and Mcm10. Mcm2, a subunit of the MCM2-7 complex, associated with chromatin periodically from early $G_{1}$ phase to the beginning of $S$ phase (Fig. $2 B$, bottom) as previously shown (Liang and Stillman 1997; Young and Tye 1997). In contrast, Mcm10 associated with chromatin throughout the cell cycle at a constant level (Fig. 2B, top). These results suggest that Mcm10 is constitutively chromatin bound.

The association of $\mathrm{Mcm} 10$ with chromatin appears to be DNA dependent. Before being fractionated into soluble and pellet fractions, the whole cell lysate was treated with DNase I, RNase A, or nonionic detergent NP-40, respectively (Fig. 2C). After the treatment, the soluble and pellet fractions were separated by centrifugation and analyzed for the presence of Mcm10 and histone H2B. Treating with RNase A (Fig. 2C, lanes 3,4), NP-40 (lanes 5,6), or the lysis buffer (lanes 7,8) had no obvious effect on the association of either Mcm10 or histone $\mathrm{H} 2 \mathrm{~B}$ with chromatin; these proteins remained chromatin bound. DNase I treatment, however, released Mcm10 completely and histone $\mathrm{H} 2 \mathrm{~B}$ partially from the chromatin pellet to the soluble fraction (Fig. 2C, lanes $1,2)$.

An in vivo cross-linking immunoprecipitation technique has been adopted successfully to localize several replication proteins on replication origins (Aparicio et al. 1997; Tanaka et al. 1997; Tanaka and Nasmyth 1998), although the biochemical nature of the origin binding of some of these proteins, such as Cdc6 and MCM2-7, remains elusive. Using this technique, we were able to demonstrate the association of $\mathrm{Mcm} 10$ with origin DNA. A strain in which Mcm10 was epitope tagged at the carboxyl terminus with c-Myc was constructed. This tagged strain, as well as a wild-type strain, was treated with formaldehyde to induce cross-linking. Lysates from cells with or without cross-linking were immunoprecipitated using anti-Myc antibodies. The presence of origin sequence in the immunoprecipitate was examined by PCR amplification (Fig. 2D). Lanes 1 and 6 in Figure 2D show that both ORI1 (200 bp) and the control DNA (240 bp) can be detected in cell lysates. Lanes 2, 3, 7, and 8 show that without cross-linking, neither DNA fragments were precipitated. Lanes 4, 5, 9, and 10 show that in the cross-linked cells, ORI1, but not R2.5 (the 240-bp sequence $2.5 \mathrm{~kb}$ away from the origin), was precipitated from the Mcm 10-Myc strain after immunoprecipitation. This result suggests that at least some of the chromatin bound Mcm 10 is localized to replication origins and that the pausing of elongation forks at ORI1 may result from a change in chromatin structure induced by the Mcm10-1 mutant protein.

Binding of Mcm10 to chromatin is essential for the chromatin association of $\mathrm{Mcm} 2$, but not $O R C$, during $G_{1}$ phase

The interaction between Mcm10 and the MCM2-7 proteins as well as the localization of Mcm10 at ORI1 suggests that Mcm10 is likely a component of the pre-RC. To investigate whether Mcm10 plays a role in the formation and maintenance of the pre-RC, we examined the chromatin association of $\mathrm{Mcm} 2$ and Orc3, a subunit of ORC, when Mcm10 is removed from chromatin. This experiment was performed using temperature-sensitive mcm10 mutant cells synchronized in $\mathrm{G}_{1}$ phase, because MCM2-7 proteins are associated with chromatin only during $\mathrm{G}_{1}$ phase. $m c m 10$ mutant cells were arrested at the $\mathrm{G}_{1}$ phase with $\alpha$ factor at $30^{\circ} \mathrm{C}$ and then shifted to $37^{\circ} \mathrm{C}$ in the presence of additional $\alpha$ factor. Cells were harvested at 1 -hr intervals up to $5 \mathrm{hr}$ after the temperature shift and fractionated as described above. The chromatin-enriched pellet fractions were analyzed for the presence of Mcm10, Orc3, Mcm2, and histone H2B. Two temperature-sensitive $\mathrm{mcm} 10$ mutants, $\mathrm{mcm} 10$-1 (Merchant et al. 1997), and mcm10-43 (Solomon et al. 1992) were examined. These two mutant alleles showed similar phenotypes in two-dimensional DNA gel analysis (M. Lei, unpubl.). When cells were shifted to the restrictive temperature, the binding of the Mcm10-1 protein to chromatin was not affected (data not shown). However, Mcm10-43 is released gradually from the chromatin fraction (Fig. 3A, a) into the soluble fraction (Fig. 3A, b) during this time course. The removal of Mcm10 had no effect on the chromatin association of Orc3. Orc3 remained associated with chromatin throughout the time course (Fig. 3A, c). However, as Mcm10 was removed from chromatin, Mcm2 was also released from chromatin (Fig. 3A, d). Both Mcm10 and Mcm2 remained associated with chromatin $5 \mathrm{hr}$ after shift to $37^{\circ} \mathrm{C}$ in a wildtype strain (Fig. 3C, a,b). As a control, the chromatin binding of histone $\mathrm{H} 2 \mathrm{~B}$ remained constant throughout the time course (Fig. 3A, e). Thus, the chromatin association of $\mathrm{Mcm} 2$, but not that of Orc3, depends on the stable association of Mcm 10 with chromatin.

To investigate whether the binding of Mcm10 to chromatin depends on the association of ORC with chromatin, we carried out a similar temperature shift experiment using the temperature-sensitive orc2-1 mutant and examined the chromatin association of Mcm10 and Mcm2, when Orc3 is removed from chromatin. The orc2-1 mutation severely affects the formation of the ORC complex and its chromatin binding (Bell et al. 1993). Consistent with this observation, we found that the chromatin association of Orc3 is significantly compromised in this mutant. Subunits of ORC, which are found only in the chromatin fraction in wild-type cells (Fig. 3C, c) (Liang and Stillman 1997), were detected in the soluble fraction in the orc2-1 mutant even at a permissive temperature (Fig. 3B, b). Shifting to the restric- 
A

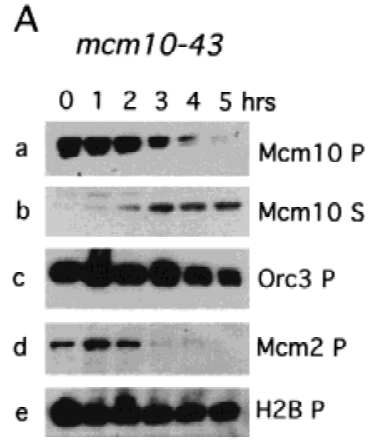

B
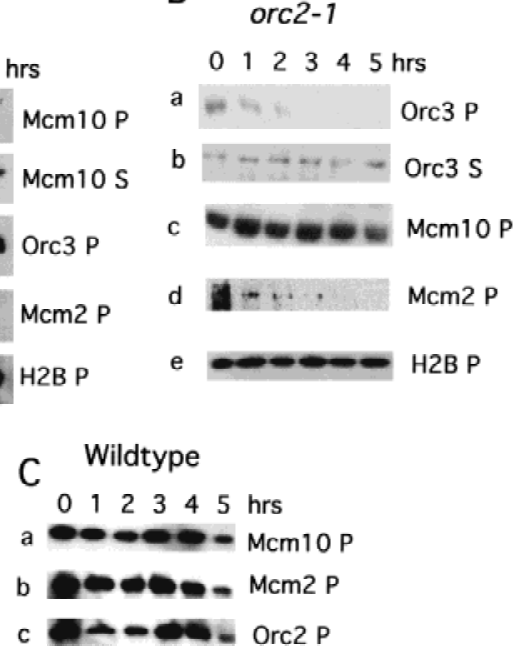

Figure 3. Mcm10 is required for the binding of the MCM2-7 complex to chromatin. (A) Chromatin binding of Mcm10, Orc3, $\mathrm{Mcm} 2$, and histone $\mathrm{H} 2 \mathrm{~B}$ during $\mathrm{G}_{1}$ phase in MW23 cells (a ura353 can1-11 mcm10-43) (Solomon et al. 1992). Cells were treated with $\alpha$ factor $(10 \mu \mathrm{g} / \mathrm{ml})$ for $3 \mathrm{hr}$ at $30^{\circ} \mathrm{C}$ and again with the same amount before being shifted to $37^{\circ} \mathrm{C}$ for $0-5 \mathrm{hr}$ (lanes 1-5). Pellet $(\mathrm{P})$ and soluble fractions $(\mathrm{S})$ were prepared as described in Fig. 2, and analyzed in SDS-PAGE. Western blots were probed with antibodies specific for $\mathrm{Mcm} 10$, Orc3, Mcm2, or histone $\mathrm{H} 2 \mathrm{~B}$ as indicated. (B) Chromatin binding of Orc3, Mcm10, Mcm2, and histone H2B during $\mathrm{G}_{1}$ phase in JRY4490 cells (a can1-1 his3-11 leu2-3, -112 lys2s trp1-1 ura3-1 orc2-1) (Foss et al. 1993). Cells were treated with $\alpha$ factor $(10 \mu \mathrm{g} / \mathrm{ml})$ for $3 \mathrm{hr}$ at $25^{\circ} \mathrm{C}$ and again with the same amount before being shifted to $37^{\circ} \mathrm{C}$ for $0-5 \mathrm{hr}$ (lanes $1-5$ ). Pellet and soluble fractions were analyzed in SDS-PAGE. Western blots were probed with antiMcm10, anti-Orc3, anti-Mcm2, or anti-histone H2B as indicated. The anti-Orc3 antibody was a gift from Bruce Stillman (Cold Spring Harbor Laboratory) and the anti-H2B antibody was a gift from Mike Grunstein (UCLA). (C) Mcm10, Mcm2, and Orc2 are associated with chromatin in the presence of $\alpha$ factor after $5 \mathrm{hr}$ of incubation at $37^{\circ} \mathrm{C}$ in the W303barl strain.

tive temperature completely removed Orc3 from chromatin in the mutant (Fig. 3B, a). The binding of Mcm10 to chromatin was not affected. Mcm10, like histone $\mathrm{H} 2 \mathrm{~B}$, remained associated with chromatin up to $5 \mathrm{hr}$ after shifting to the restrictive temperature (Fig. 3B, c,e). Thus, the chromatin association of Mcm10 was not dependent on that of Orc3. Orc2-1 also had a profound impact on the chromatin binding of $\mathrm{Mcm} 2$. At $3 \mathrm{hr}$, $\mathrm{Mcm} 2$ is dissociated completely from chromatin much like Orc3 (Fig. 3B, d). Taken together, our results suggest that during the $\mathrm{G}_{1}$ phase, the binding of MCM2-7 to chromatin is dependent on the binding of both ORC and Mcm10; the binding of Mcm10 is not dependent on, nor required for the binding of ORC to chromatin, and vice versa.

The heat sensitivity of mom10-1 is suppressed by an independently isolated mutant allele of the replication initiation factor $\mathrm{Mcm} 7$

To elucidate the role played by Mcm10 in replication initiation, genetic interactions were examined by crossing mcm10-1 with known mutants of the MCM2-7 family. Known mutants in MCM2-7 were initially identified by one of two strategies. Some mutants were identified by their $\mathrm{mcm}$ (minichromosome maintenance) defects (Maine et al. 1984), whereas others were identified by

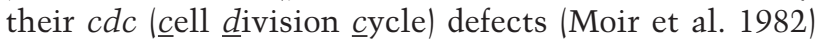
but were later assigned a $\mathrm{mcm}$ notation (Table 1; Chong et al. 1995; Kearsey et al. 1995). Throughout this paper, we will use the $\mathrm{mcm}$ nomenclature for all mutants of the MCM2-7 family in the interest of clarity.

The results of sporulation and dissection are shown in Table 1. To determine the phenotypes of the double mutants, we examined the growth pattern of the tetratype (TT) tetrads. Because MCM10 is not linked to any of the MCM2-7 genes, statistically, four of every six tetrads are the tetratype. A TT tetrad consists of a wild-type spore, one spore for each parental mutant, and one spore for the double mutant. Because the phenotypes of all parental mutants are known, the phenotype of the double mutant spore can be easily discerned. Most crosses between parents with unlinked heat-sensitive mutant alleles gave a 3:1 heat-sensitive: heat-resistant TT pattern of growth, indicating that the double mutant was heat sensitive like the parental strains. However, in two of the crosses, mcm10-1 x mcm7-1 (cdc47-1) and mcm10-1 x mcm5$461(\operatorname{cdc} 46-1)$, the TT tetrads had two spores that grew well at $37^{\circ} \mathrm{C}$, indicating that the double mutant does not have the heat-sensitive phenotype of the parents (Fig. $4 \mathrm{~A})$.

To confirm that the inferred double mutant did contain both temperature-sensitive alleles of mcm7-1 and

Table 1. Double mutant phenotypes of $\mathrm{mcm} 10-1$ with alleles of $\mathrm{mcm} 2-\mathrm{mcm} 7$ or $\mathrm{cdc} 45$

\begin{tabular}{lcccc}
\hline & & & \multicolumn{3}{c}{$\begin{array}{c}\times \text { mcm10-1 } \\
\text { double mutant } \\
\text { phenotype }\end{array}$} \\
\cline { 3 - 5 } Mutant & Phenotype & $30^{\circ} \mathrm{C}$ & $37^{\circ} \mathrm{C}$ & $14^{\circ} \mathrm{C}$ \\
\hline$m c m 2-1$ & ts & ++ & $-{ }^{*}$ & ++ \\
mcm3-1 & ts & ++ & - & ++ \\
$m c m 4-1(c d c 54-1)$ & cs & ++ & - & - \\
mcm5-461 $(c d c 46-1)$ & ts & ++ & + & ++ \\
$m c m 5-462(c d c 46-2)$ & ts & ++ & - & ++ \\
$m c m 5-463(c d c 46-3)$ & ts & ++ & - & ++ \\
$m c m 5-465(c d c 46-5)$ & ts & ++ & - & ++ \\
$m c m 7-1(c d c 47-1)$ & ts & ++ & ++ & ++ \\
$c d c 45-1$ & cs & - & - & -
\end{tabular}

The phenotype of each parental strain is shown, as well as the phenotypes of double mutants obtained by crossingg to $\mathrm{mcm} 10$ 1. The mcm10-1 mutant is temperature-sensitive with a restrictive temperature of $37^{\circ} \mathrm{C}$. We see strong suppression between mcm10-1 and mcm7-1, weak suppression between mcm10-1 and $m c m 5-461$, and synthetic lethality between mcm10-1 and $c d c 45-1$. The original $c d c$ notations used for the $\mathrm{mcm} 4, \mathrm{mcm} 5$, and $\mathrm{mcm} 7$ mutants are shown in parentheses.

a(ts) Heat sensitive; (cs) cold sensitive.

$\mathrm{b}(+)$ growth; $(-)$ no growth. $\left({ }^{\star}\right)$ The restrictive temperature for mcm2-1 is $38^{\circ} \mathrm{C}$. 


\section{A Segregation of two unlinked markers in tetrads is PD : NPD : TT = 1: $1: 4$}

\begin{tabular}{|c|c|rl|}
\hline cross & $\begin{array}{c}\text { tetrad pattern } \\
\text { (ts }: \text { wt) }\end{array}$ & \multicolumn{2}{|c|}{$\begin{array}{c}\text { number of tetrads } \\
\text { (inferred spore type) }\end{array}$} \\
\hline & $2: 2$ & 10 & (TT) \\
$m c m 10-1 \times m c m 7-1$ & $4: 0$ & 2 & (PD) \\
& $0: 4$ & 1 & (NPD) \\
\hline
\end{tabular}

B $m c m 10-1 \times m c m 7-1$
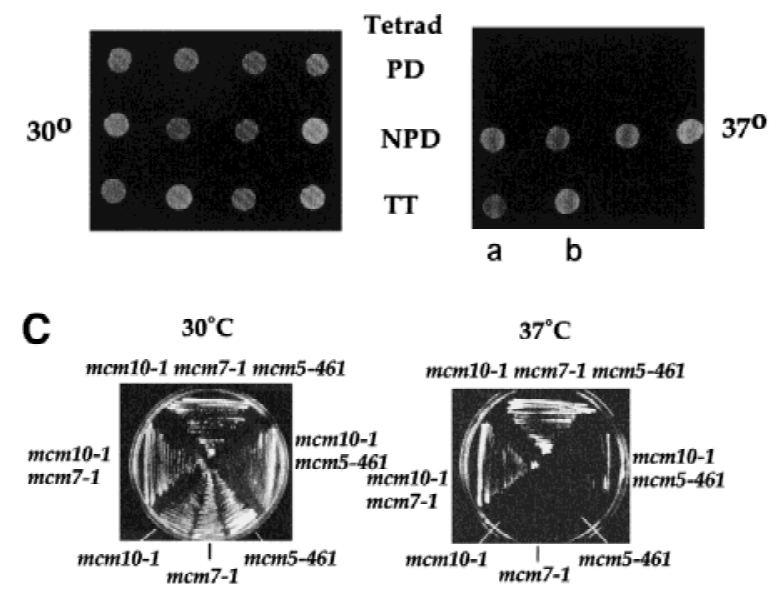

\begin{tabular}{ll} 
D & Doubling Time $\left(37^{\circ} \mathrm{C}\right)$ \\
\cline { 2 - 2 } DBY2055 parent & $2.1 \mathrm{hr}$ \\
$m c m 10-1$ & $5.8 \mathrm{hr}$ \\
$m c m 5-461$ & $6.1 \mathrm{hr}$ \\
$m c m 7-1$ & dead \\
$m c m 10-1 m c m 5-461$ & $5.1 \mathrm{hr}$ \\
$m c m 10-1 m c m 7-1$ & $4.6 \mathrm{hr}$ \\
$m c m 10-1$ mcm5-461 & $2.9 \mathrm{hr}$
\end{tabular}

Figure 4. Tetrad analyses of diploids from a cross between R125A22-2C (mcm10-1) and DBY2029 (mcm7-1). (A) Segregation patterns of phenotypes indicate that the double mutant is wild type, although both parental strains are temperature sensitive (ts). (TT) Tetratype; (PD) parental ditype; (NPD) nonparental ditype. Both parental strains are ts. $(B)$ Growth phenotypes of spores from typical tetrads from a cross between mcm10-1 and mcm7-1. Viable spores of a TT tetrad were further analyzed by crossing with a wild-type strain. $(C)$ Growth phenotypes of yeast strains LHY1A (mcm10-1 mcm7-1), LHY4B (mcm10-1 mcm5-461), and LHYTM18C (mcm10-1 mcm7-1 mcm5-461) after 3 days on YEPD plates at $30^{\circ} \mathrm{C}$ and $37^{\circ} \mathrm{C}$. (D) Growth rates of the single, double, and triple mutants of mcm10-1, mcm5-461, and mcm7-1. Strains were grown overnight in YPD at $30^{\circ} \mathrm{C}$, then diluted to $\mathrm{OD}_{600}=0.1$. Diluted cultures were kept at $30^{\circ} \mathrm{C}$ for $30 \mathrm{~min}$ then shifted to $37^{\circ} \mathrm{C}$ for 10 hr. Doubling times were calculated from growth curves. The mcm7-1 strain did not grow after shift to $37^{\circ} \mathrm{C}$.

mcm10-1, the two heat-resistant spores from a typical TT tetrad were crossed back to wild-type cells individually. From these crosses, one of the spores (Fig. 4B, a) from each tetrad always gave back only wild-type spores, implying that it itself is wild type (data not shown).
When the second spore (Fig. 4B, b) was crossed to wildtype cells, TT tetrads yielded temperature-sensitive spores that could be complemented by transformation with either MCM10 or MCM7 on a single copy plasmid (data not shown). Therefore, we concluded that the second spore was the double mutant. Although mcm10-1 and $m c m$ 7-1 were independently isolated, our data suggest that they synthetically cosuppress the heat-sensitive defects of both parents (Fig. 4B,C).

The mutual suppression phenotype of the $\mathrm{mcm} 10-1$ mcm7-1 double mutant was checked for growth at $37^{\circ} \mathrm{C}$ on plates (Fig. 4C) and by FACS analysis (data not shown). At the restrictive temperature for the single mutants, the double mutant grew well (Fig. 4C). By FACS analysis, mcm10-1 and mcm7-1 both arrested with nearly two genome equivalents (2C) of DNA after $3 \mathrm{hr}$ at $37^{\circ} \mathrm{C}$. However, the double mutant did not arrest and cells with a DNA content of $1 \mathrm{C}$ and $2 \mathrm{C}$ were well represented in the population under the same conditions.

Mutual suppression was also seen in $\mathrm{mcm} 10-1 \mathrm{mcm} 5$ 461 (cdc46-1) double mutants, although the growth rate of this double mutant at $37^{\circ} \mathrm{C}$ is lower than wild-type levels (Table 1; Fig. 4C). There is some suppression of the temperature-sensitive phenotype in this double mutant because no growth was apparent on plates containing double mutants of mcm10-1 paired with other mutants of the MCM2-7 family, including $m c m 2-1, m c m 3-1$, and mcm4-1 (cdc54-1) (Table 1). In addition, the mcm5-461 mcm10-1 strain has a shorter doubling time at $37^{\circ} \mathrm{C}$ than either $m c m 10-1$ or $m c m 5-461$ alone (Fig. 4D). This suppression is allele specific; a double mutant of mcm10-1 with other alleles of $\mathrm{mcm} 5$ did not show suppression of the temperature sensitivity (Table 1), nor did double mutants of $m c m 5-461$ with another $m c m 10$ allele $(\mathrm{mcm} 10$ 43; data not shown).

Double mutants of mcm5-461 mcm7-1 are synthetically lethal (Hennessy et al. 1991) suggesting that two defective subunits of the MCM2-7 complex are detrimental to yeast cells. Because $m c m 10-1$ is able to suppress each of these mutations individually, we tested the combined effects of the triple mutant mcm10-1 mcm5$461 \mathrm{mcm} 7-1$. Interestingly, the triple mutant was viable (Fig. 4C), indicating that the specific defects of the Mcm5 and $\mathrm{Mcm} 7$ mutant proteins could be simultaneously suppressed by the altered Mcm10-1 protein within the same cell. We also noted that the suppression of the mcm10-1 heat-sensitive phenotype was more complete in the triple mutant than in the mcm10-1 mcm5-461 or mcm10-1 mcm7-1 double mutant as shown by growth on plates and in culture (Fig. 4C,D). The doubling time of the triple mutant at $30^{\circ} \mathrm{C}$ and $37^{\circ} \mathrm{C}$ was 2.6 and $2.9 \mathrm{hr}$, respectively, compared to 3.3 and $5.1 \mathrm{hr}$ for the $\mathrm{mcm} 5$ $461 \mathrm{mcm} 10-1$ mutant, and 2.7 and $4.6 \mathrm{hr}$ for the $\mathrm{mcm} 7-1$ mcm10-1 double mutant (Fig. 4D).

Replication initiation is restored and fork barriers are obliterated in the mcm10-1 mcm7-1 double mutant

The role of Mcm10 and other MCM proteins in DNA replication were first identified by the poor ability of 
their mutants to maintain minichromosomes, which are plasmids containing an origin of replication (ORI) and a centromere (CEN) (Maine et al. 1984). To determine whether the high plasmid loss phenotypes of the mcm10-1 and mcm7-1 strains were alleviated in the double mutant, plasmid stability assays were performed. Using minichromosomes carrying autonomously replicating sequence (ARS) fragments from different regions of the genome, minichromosome maintenance defects were observed for both mcm10-1 and mcm7-1 (Fig. 5A). However, double mutants of mcm10-1 mcm7-1 derived from spores of two different tetrads support the replication of plasmids at wild-type levels (Fig. 5A). This result suggests that the replication defects of the single mutants are suppressed in the double mutant.

To investigate whether the double mutant both restores the competence to initiate DNA synthesis at replication origins and abolishes the pausing of elonga- tion forks, the activities of ORI1 in the double mutant were examined. Two-dimensional gel analysis showed that both mcm10-1 and mcm7-1 have reduced origin firing, which was visualized by a reduced intensity of the bubble arc signal (Fig. 5B). In contrast, the mcm10-1 mcm7-1 double mutant restores this origin firing to a level comparable to that of the wildtype strain. Two species of $\mathrm{Y}$ form replicative intermediates that accumulate in two spots of intense signals, one strong and one weak, in the mcm10-1 mutant, as indicated by arrows. These intense signals result from the pausing of migrating replication forks as they pass through ORI1 from opposite directions. However, pause signals are completely abolished in the double mutant, indicating that the block to replication forks traversing through the origin is removed. Thus, mcm10-1 mcm7-1 mutants do not display any of the defects that are observed in each of the single mutants.
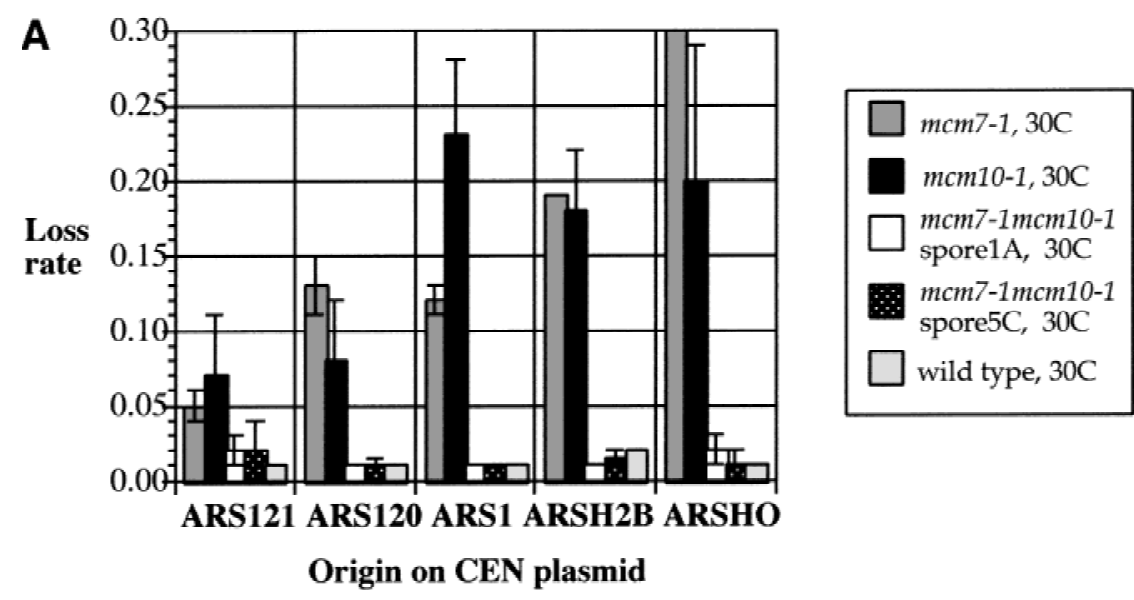

B

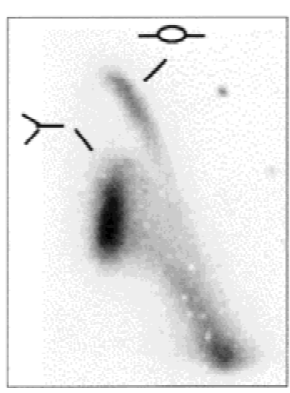

wild type

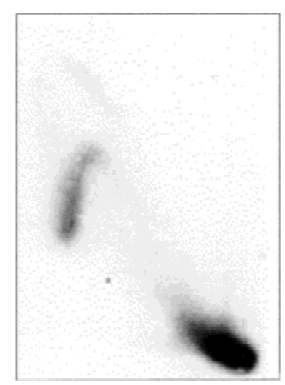

$\operatorname{mcm} 7-1$

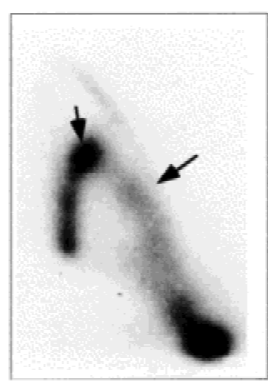

mcm10-1

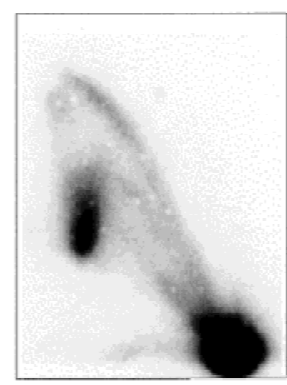

mcm10-1 mcm7-1

Figure 5. Replication defects of the mcm10-1 and mcm7-1 single mutants are corrected in mcm10-1 mcm7-1. (A) Stability of plasmids in single and double mutants of $m c m 10-1$ and $m c m 7-1$. Plasmid loss rates were determined for the single mutants $m c m 7-1$ and mcm10-1, as well as for two double mutants (LHY1A and LHY5C) and a wild-type strain (8534-8c) at $30^{\circ} \mathrm{C}$. Five different minichromosomes each containing a different ARS were used in this assay. The corresponding ARS of each minichromosome (e.g., ARS121, ARS120) is indicated on the $x$-axis. The $y$-axis shows the rates of plasmid loss per cell per generation. $(B)$ The double mutant relieves the pause phenotype of mcm10-1. Two-dimensional DNA gel analysis of mcm10-1 mcm7-1. Genomic DNA was isolated from the wild-type (8534-8c), mcm10-1, mcm7-1, and mcm10-1 mcm7-1 strains. Genomic DNA was digested with NcoI, separated on twodimensional gel, blotted, and probed with ${ }^{32} \mathrm{P}$-labeled ORI1 DNA. Bubble and Y arcs are indicated by cartoons on the blot showing the DNA from the wild-type strain. Pause signals that result from accumulation of specific species of replication intermediates are indicated by arrows. 


\section{Mutual suppression is dominant}

The mutual suppression between mcm10-1 and mcm7-1 could be the result of the neutralization of two antagonists. If so, suppression is due to a loss of function and therefore, would be recessive. On the other hand, the mutual suppression could be the result of the restoration of physical contact between two interacting proteins, a gain of function scenario. In this case, the suppression should be dominant. To determine whether the mutual suppression between mcm10-1 and mcm7-1 is dominant, diploid strains heterozygous for mcm10-1 and homozygous for mcm7-1 or heterozygous for mcm7-1 but homozygous for $\mathrm{mcm} 10-1$ were constructed. The resulting diploids both grew well at $37^{\circ} \mathrm{C}$ (data not shown) indicating that the mutual suppression is dominant and likely due to the restoration of physical contact between the two mutant proteins.

Overexpression studies can also lend support for a physical interaction model. An increase in the level of one of two poorly interacting proteins can provide more opportunity for the crippled physical interaction to occur. We overexpressed Mcm7 in a mcm10-1 strain and Mcm10 in a mcm7-1 strain by transforming the strains with high copy plasmids. In both cases, an increased level of growth was seen for the transformants at $37^{\circ} \mathrm{C}$ (data not shown). These results also support a model in which increased physical contact between the two mutant proteins alleviates their individual defects.

\section{Mutual suppression of mcm 10-1 and mcm7-1 is due to the restoration of physical interaction between the two mutant proteins}

The restoration of physical interaction between the mutant proteins is illustrated in Figure 6A. Mcm10 and Mcm7 (XY) were shown previously to physically interact by two-hybrid analysis (Merchant et al. 1997), therefore it is possible that the mutations in each protein individually abolish this interaction (Xy or $\mathrm{xY}$ ). When both proteins are altered in a specific manner, however, perhaps the interaction can be restored (xy). To test this hypothesis, two-hybrid analysis was performed. Fusion proteins were created between each mutant or wild-type protein and the Gal4 activation domain (GAD) or the Gal4-binding domain (GBD). These were transformed by pairs into PJ69-4a cells containing the $\beta$-galactosidase reporter
A

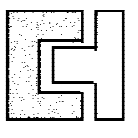

X

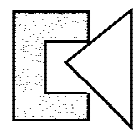

$x \quad y$
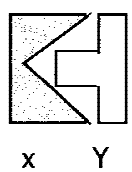

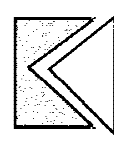

$x \quad y$

\begin{tabular}{|c|c|c|c|}
\hline Cros & \multicolumn{2}{|c|}{$m c m 7-1 \times m c m 10-43$} & \\
\hline Ascus type & \# found & ts:wt & inferred genotype \\
\hline PD & 8 & $4: 0$ & $2 \mathrm{mcm} 7-1: 2 \mathrm{mcmlO}^{-}-43$ \\
\hline NPD & 12 & $2: 2$ & $2 \mathrm{mcm} 7-1 \mathrm{mcm} 10-43: 2 \mathrm{wt}$ \\
\hline $\mathrm{TT}$ & 37 & $3: 1$ & $\begin{array}{l}1 \mathrm{mcm} 7-1: 1 \mathrm{mcm} 10-43: \\
1 \mathrm{mcm} 7-1 \mathrm{mcm} 10-43: 1 \mathrm{wt}\end{array}$ \\
\hline
\end{tabular}

$E$

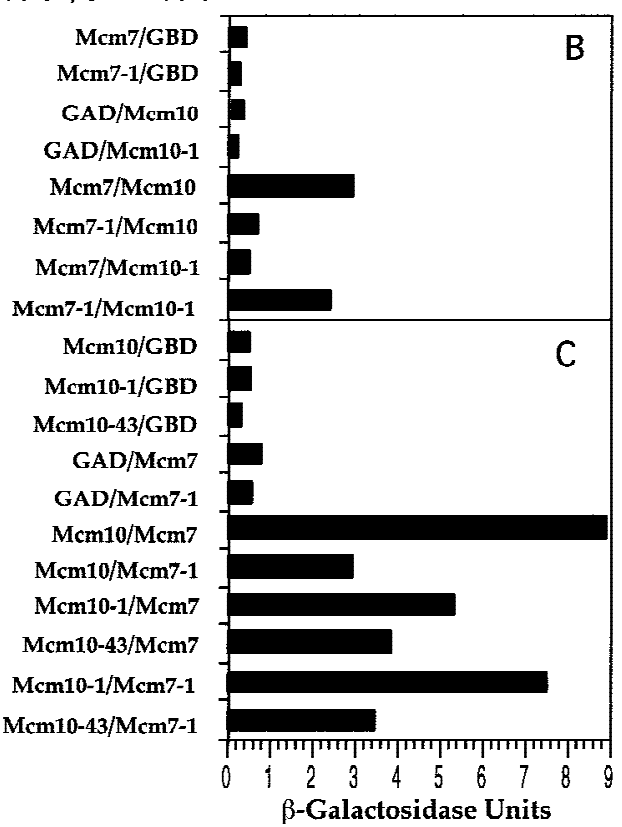

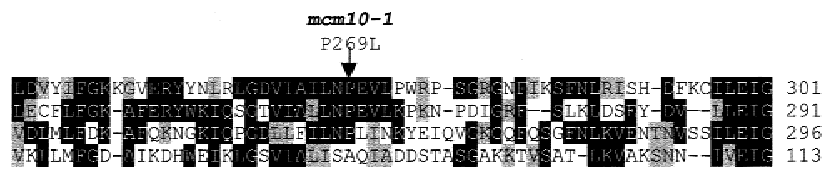

mam10-43

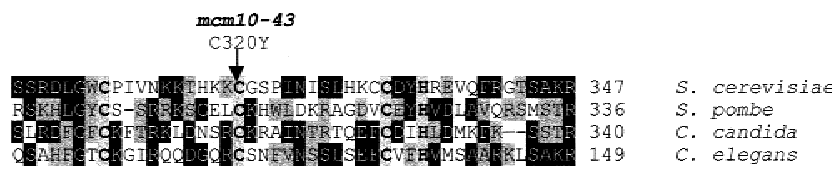

Zinc finger

c $\times 9-10$ c $\times 11$

$\mathrm{C} \times 2 \mathrm{H}$

Figure 6. Interactions between wild-type and mutant $\mathrm{Mcm} 7$ and $\mathrm{Mcm} 10$ proteins. (A) Model to explain the mutual suppression of two mutant proteins by compensatory mutations that restore physical interactions. (Wildtype proteins) $\mathrm{X}$ and $\mathrm{Y}$; (mutant proteins) $\mathrm{x}$ and $\mathrm{y}$. (B) Physical interactions between wild-type and mutant proteins of $\mathrm{Mcm} 10$ and $\mathrm{Mcm} 7$ measured by $\beta$-galactosidase activity using the two-hybrid system. Mcm7 is fused to the Gal4 activation domain and Mcm10 is fused to the Gal4-binding domain. (C) Same as $B$ with bait and prey in reverse orientations. The Mcm10-43 mutant protein is also included in the analysis. $(D)$ Tetrad analyses of diploids from a cross between DBY2029 (mcm7-1) and mcm10-43. $m \mathrm{~cm} 7-1$ was crossed with mcm10-43 in two different backgrounds (BTY106 and BTY103), and data were combined. The inferred genotypes indicate that the double mutant is temperature sensitive (ts). (TT) Tetratype; (PD) parental ditype; (NPD) nonparental ditype; (ts) temperature sensitive; (wt) wild-type phenotype. Both parental strains are ts. $(E)$ Evolutionary conservation of the Mcm 10 protein. The $\mathrm{mcm} 10-1$ and mcm10-43 mutations are indicated above the aligned sequences of putative homologs of Mcm10: (Cdc23) S. pombe; (Con4-2907) C. albicans; (WPY47D3) C. elegans. Both mutations occur in regions conserved between S. cerevisiae and S. pombe. Black boxes indicate consensus. Gray boxes indicate similarity to consensus. Consensus zinc finger motif is shown at the bottom. 
gene downstream of a GAL4-inducible promoter (James et al. 1996). The levels of interaction between the mutant and wild-type proteins were measured by $\beta$-galactosidase activity as shown in Figure 6, B and C.

The physical interactions between $\mathrm{Mcm} 10$ and $\mathrm{Mcm} 7$ were tested in two different orientations in the two-hybrid system. In one orientation, $\mathrm{Mcm} 7$ proteins were fused to the GAD and Mcm 10 proteins fused to the GBD (Fig. 6B). In another orientation, Mcm10 proteins were fused to the GAD and Mcm7 proteins to the GBD (Fig. 6C). To test the specificity of interaction, two $\mathrm{mcm} 10$ mutant alleles were used: $m c m 10-1$ and $m c m 10-43$ (Fig. 6C). There is a significant decrease in the level of interaction between the proteins when either Mcm10 or Mcm7 is mutated (Fig. 6B,C). A specific mutant pair, Mcm7-1 and Mcm10-1, however, interacts as strongly as the two wild-type proteins (Fig. 6B,C). This strong interaction is observed in both orientations of activation and binding domain fusions. In contrast, when the mutant pair Mcm10-43 and Mcm7-1 was tested, the interaction is comparable to that observed when only one of the proteins is mutant but significantly less than that observed between the wild-type proteins or the Mcm10-1 and Mcm7-1 combination (Fig. 6C).

This result suggests that restoration of interaction between Mcm 10 and Mcm7 mutant proteins is allele specific. If interaction between $\mathrm{Mcm} 10$ and $\mathrm{Mcm} 7$ is a prerequisite for normal functions of these proteins, then the mcm10-43 mcm7-1 double mutant should not be viable at the restrictive temperature of the single mutants. To test this, we crossed the mutant strains of mcm7-1 and mcm10-43 and dissected tetrads. The TT tetrads yielded one wild type spore and three Ts spores, indicating that the double mutant is temperature sensitive for growth (Fig. 6D). Similar results were obtained in a cross between mcm5-461 and mcm10-43, suggesting that there is no suppression between these mutant alleles (data not shown).

\section{Amino acid changes that affect interactions between $\mathrm{Mcm} 10$ and $\mathrm{Mcm} 7$}

The mcm7-1 mutation has been shown previously to be a change from serine to tyrosine at position 286 (Dalton and Hopwood 1997) in the amino-terminal portion of Mcm7. We have now determined the sequence of the two mcm10 mutant alleles-mcm10-1, which was identified initially as a minichromosome maintenance defective mutant (Maine et al. 1984; Merchant et al. 1997), and mcm10-43, alias dna43, which was originally identified for its defect in DNA synthesis (Solomon et al. 1992). Both alleles are the result of single nucleotide substitutions resulting in single amino acid changes. The mcm10-1 mutation is a proline to leucine substitution at amino acid 269 and $m c m 10-43$ is a cysteine to tyrosine change at residue 320 (Fig. 6E). Both mutations disrupt the interaction between Mcm10 and Mcm7, but only one of them, P269L, is suppressed by the mcm7-1 mutation, suggesting that the restoration of interaction be- tween Mcm10 and Mcm7 may be defined by specific contacts between the two proteins.

Recently, a homolog of MCM10 has been identified in Schizosaccharomyces pombe (Aves et al. 1998). The $c d c 23^{+}$gene of $S$. pombe has been shown to complement a Saccharomyces cerevisiae mcm10 null strain (Y. Kawasaki, unpubl.). The Cdc23 ORF encodes a putative protein of 593 amino acids that is only $17 \%$ identical but almost $60 \%$ similar to Mcm10. An ORF (con4-2907) in the Candida albicans genome data base and another (WPY47D3) in the Caenorhabditis elegans genome data base also show significant similarities with Mcm10 in this region of about 85 amino acids (Fig. 6E). Alignment of these four sequences indicates that P269 is conserved in the yeast homologs, though not in C. elegans. However, C320 is conserved in all four sequences in a region that encodes a putative zinc finger motif of the type $\mathrm{CX}_{9-10} \mathrm{CX}_{11} \mathrm{CX}_{2} \mathrm{H}$ (Fig. 6E).

\section{Genetic interactions between MCM10 and CDC45}

The two mutant alleles, mcm5-461 and mcm7-1, which suppress the heat-sensitive growth defect of mcm10-1 but not that of $m c m 10-43$, were identified originally as extragenic suppressors that alleviate the cold-sensitive growth defect of the $c d c 45-1$ mutant (Moir and Botstein 1982; Fig. 7A). Cdc45 is a protein factor essential for DNA replication initiation. The cdc45 mutant allele shows a cell cycle arrest phenotype that is typical of replication initiation mutants, that is, large budded cells with a DNA content of 1C (Hennessy et al. 1991). Physical interactions of Cdc45 with Mcm5 and Mcm7 have been demonstrated previously using the two-hybrid system (Dalton and Hopwood 1997) and by immunoprecipitation (Hopwood and Dalton 1996). The suppression of mcm10-1 by the suppressors of $c d c 45-1$ led us to examine the genetic interactions between CDC45 and MCM10.

To construct a double mutant that contains both the cdc45-1 and mcm10-1 mutations, we crossed the single mutant strains. Diploids were sporulated, and the results of the tetrad analysis are shown in Figure 7B. A majority of the resulting tetrads contained only three live spores. Several tetrads contained only two live spores, and in these cases the two spores were wild type for growth at $37^{\circ} \mathrm{C}$ and $14^{\circ} \mathrm{C}$. The only four-spore tetrads contained two heat-sensitive and two cold-sensitive spores, the phenotype of a parental ditype (PD) tetrad. The pattern of spore viability of the tetrads was consistent with synthetic lethality of the mcm10-1 and $c d c 45-1$ mutations (Fig. 7A). Further tetrad analysis of diploids carrying a MCM10-containing plasmid confirms the lethality of the mcm10-1 cdc45-1 double mutant (data not shown). Tetrad analysis of a cross between $c d c 45-1$ and mcm1043 also suggests synthetic lethality in the $c d c 45-1$ mcm10-43 double mutant (data not shown).

\section{Discussion}

Mcm10 is an essential protein that plays a pivotal role in DNA replication. The identification of Mcm10 ho- 


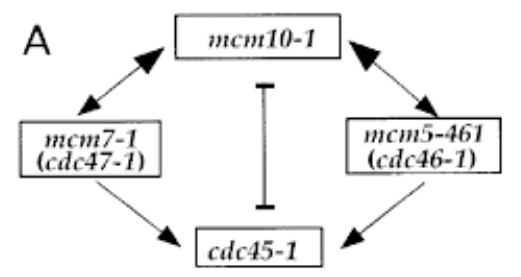

B

\begin{tabular}{|c|c|}
\multicolumn{1}{c}{$m c m 10-1 \times c d c 45-1$} \\
\hline $\begin{array}{c}\text { spore pattern } \\
\text { (wt: ts : cs : non-viable) }\end{array}$ & no.of tetrads \\
\hline $0: 2: 2: 0$ & 3 (PD) \\
\hline $2: 0: 0: 2$ & 3 (NPD) \\
\hline $1: 1: 1: 1$ & 12 (TT) \\
\hline
\end{tabular}

$\mathrm{C}$ (a)

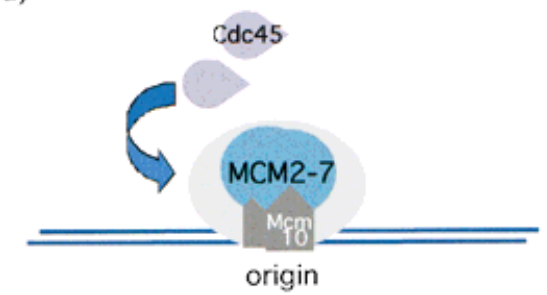

(b)

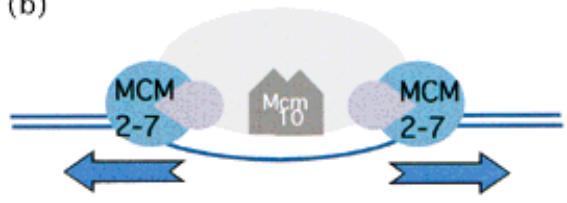

Figure 7. (A) Genetic interactions between mcm10-1, cdc45-1, mcm5-461 (cdc46-1), and mcm7-1 (cdc47-1). mcm5-461 and mcm7-1 are synthetic lethal mutations that were originally isolated as suppressors of the cold-sensitive cdc45-1 mutation (Hennessy et al. 1991; Moir et al. 1982). Arrow indicates suppression, double-headed arrow indicates mutual suppression, bar indicates synthetic lethality. $(B)$ Genetic spore segregation patterns of tetrads derived from a cross between mcm10-1 and cdc45-1. Inferred spore types are shown in parentheses. $(C) \mathrm{A}$ model to explain the observations that allele-specific suppressors of mcm10-1 in the MCM2-7 gene family are also suppressors of $c d c 45-1$. We hypothesize that the site on Mcm7 that contacts $\mathrm{Mcm} 10$ is also used to contact Cdc45, although these contacts may not occur at the same time. (a) The association of the MCM2-7 complex with a replication origin is mediated through $\mathrm{Mcm} 10$ by interactions with $\mathrm{Mcm} 7$ and possibly other subunits of the complex during $G_{1}$ phase. Cdc45 is recruited to the pre-RC just before the $\mathrm{G}_{1}$ phase to S-phase transition (Zou and Stillman 1998). (b) In this model, displacement of MCM2-7 from $\mathrm{Mcm} 10$ by $\mathrm{Cdc} 45$ is a critical step in the activation of replication initiation. Once initiation has occurred, Cdc45 and MCM2-7 may comigrate from the replication origin in concert with the elongation machinery (Aparicio et al. 1997). The large gray oval shape in $a$ and $b$ represents, respectively, the pre-RC and post-RC in transition.

mologs in S. pombe, C. albicans, and C. elegans suggests that $\mathrm{Mcm} 10$, like other replication initiation factors, is likely to be conserved in all eukaryotes (Tye 1999). Pre- vious work has shown that Mcm10 physically interacts with multiple subunits of the MCM2-7 complex (Merchant et al. 1997). Here, we show that Mcm10 is exclusively bound to chromatin throughout the cell cycle and is also localized at a replication origin, ORI1. Association of the MCM2-7 complex with the prereplicative chromatin during $\mathrm{G}_{1}$ phase is dependent on Mcm10. On the other hand, removal of Mcm10 from chromatin during $G_{1}$ phase has no effect on the binding of ORC and vice versa. Lesions in Mcm10 induce pausing of elongation forks at ORI1 only if ORI1 is competent to initiate DNA synthesis. Interaction between $\mathrm{Mcm} 10$ and $\mathrm{Mcm} 7$, a subunit of the MCM2-7 complex, is required for the initiation of DNA synthesis at replication origins. Furthermore, this interaction contributes to the structure of the pre-RC by directly or indirectly removing a block to elongating replication forks that migrate through replication origins.

We showed that the pause phenotype of mcm10-1 is dependent on the specific interaction established between Mcm10 and Mcm7. However, disruption of interaction between Mcm10 and Mcm7 alone is not sufficient to cause the pause phenotype as the mcm7-1 mutant does not demonstrate replication fork pausing. Previously, we have shown that Mcm10 interacts with all but one subunit, Mcm5, of the MCM2-7 complex (Merchant et al. 1997). The allele-specific suppression of mcm10-1 by $m c m 5-461$ shown in this study suggests that Mcm 10 and Mcm5 may also physically interact. The observation that defects of the mcm10-1 mutant can be compensated for by changes in more than one subunit of the MCM2-7 complex is consistent with the view that Mcm10 contacts several subunits of the MCM2-7 complex at the same time. Whereas a mutation in MCM10 might simultaneously affect all interactions between $\mathrm{Mcm} 10$ and the MCM2-7 complex, mutations in any one of the subunits of the MCM2-7 complex may only affect that specific contact. This explanation is supported by the observation that the triple mutant $\mathrm{mcm} 10-1 \mathrm{mcm} 7-1 \mathrm{mcm} 5-461$ grows significantly better than either of the mcm10-1 mcm5-461 or mcm10-1 mcm7-1 double mutants (Fig. $4 \mathrm{C}, \mathrm{D})$. Restoration of interactions between Mcm10 and only one subunit of the MCM2-7 complex is not as desirable as the restoration of interactions between $\mathrm{Mcm} 10$ and two or more subunits of the MCM2-7 complex. Obviously, there are other plausible explanations for the pause phenotype that is unique to $\mathrm{mcm} 10$ mutants. It is possible that the interaction between $\mathrm{Mcm} 10$ and replication origins may also be an important factor. Testing these hypotheses will help us elucidate the full range of functions performed by Mcm10.

Suppression of the mcm10-1 phenotypes was not limited to a change in the $\mathrm{Mcm} 7$ protein, as we also observed partial suppression by a specific change in the Mcm5 protein. Furthermore, suppression of the mom10-1 defects by mutations in MCM5 and MCM7 was allele specific. What is remarkable about these observations is that neither mcm7-1 nor mcm5-461 was initially isolated as a suppressor of $\mathrm{mcm} 10-1$. We believe that this is not coincidence, but rather that mcm7-1 and 
mcm5-461 were preselected for compensation of the mcm10-1 mutation. The mcm7-1 and mcm5-461 mutations can be traced to a single origin; they were both isolated as suppressors of the cold-sensitive $c d c 45-1 \mathrm{mu}-$ tation (Fig. 7A) (Moir et al. 1982; Hennessy et al. 1991). Cdc45 is the last known factor to be recruited to the pre-RC just before the initiation of DNA synthesis (Zou et al. 1997; Zou and Stillman 1998). Previously, Cdc45 has been shown to physically interact with Mcm5 and Mcm7 (Hopwood and Dalton 1996; Dalton and Hopwood 1997). In this paper we have shown a synthetic lethal effect between $c d c 45-1$ and two different alleles of mcm10, indicating an important link between the two gene products. All of these physical and genetic interactions suggest that association of the MCM2-7 complex with Mcm10 and Cdc45 may be critical steps in the initiation of DNA synthesis. We noticed that both suppressors of the mcm10-1 mutation [mcm5-461/C183Y) (Hopwood and Dalton 1996) and mcm7-1(S286Y) (Dalton and Hopwood 1997)] are changes that result in a tyrosine substitution at the amino-terminal portion of $\mathrm{Mcm} 5$ and Mcm7, respectively.

To put into perspective the functional relationship between subunits of the MCM2-7 complex, Mcm10, and Cdc45, we will first consider the known facts about each of these proteins. Our results suggest that Mcm10 participate in the maintenance of the pre-RC by mediating the association of MCM2-7 complex with replication origins. MCM2-7 is a key component of the pre-RC (Aparicio et al. 1997; Tanaka et al. 1997). After replication initiation, the MCM2-7 complex is believed to leave the replication origins as a processive helicase at the growing forks (Kelman et al. 1999; You et al. 1999; Chong et al. 2000). Cdc45, on the other hand, is recruited to replication origins sometime during the $G_{1^{-}}$to $\mathrm{S}$-phase transition. Its recruitment to replication origins appears to occur after the activation of the $\mathrm{S}$ phase kinase, Cdc28-Clb5, Clb6 (Zou and Stillman 1998). Reciprocal shift experiments using conditional mutants suggest that Cdc45 may act in conjunction with Cdc7-Dbf4 at the beginning of S phase (Owens et al. 1997). Phosphorylation of Mcm2 by Cdc7-Dbf4 is an essential step that demarcates the beginning of S phase (Lei et al. 1997). A plausible model that requires physical interactions of the MCM2-7 complex with both Mcm10 and Cdc45 at different points of the initiation process can be envisioned as follows. In this model Mcm10 mediates the binding of MCM2-7 to replication origins during $\mathrm{G}_{1}$ phase (Fig. 7C, a). After replication initiation has occurred, disruption of this protein-protein interaction is necessary to facilitate the transition of the MCM2-7 complex from the initiation complex to the elongation machinery. Cdc45 may play the critical role of disengaging the MCM2-7 complex from the pre-RC by displacing it from Mcm 10, its anchor at the origin (Fig. 7C, b). This model is consistent with the suppression of $\mathrm{mcm} 10-1$ and $c d c 45-1$ by the same mutation in MCM7; the late arrival of Cdc45 at replication origins during the $\mathrm{G}_{1}$ - to S-phase transition (Zou and Stillman 1998); the comigration of Cdc45 with MCM2-7 from replication origins during S phase (Aparicio et al. 1997). The synthetic lethality conferred by $c d c 45-1$ and two different alleles of mcm10 is consistent with the critical roles played by Cdc45 and Mcm10 in the same pathway. This model also provides an explanation for the pause phenotype of the mcm10-1 mutant by suggesting that failure to dislodge certain factors at replication origins may create temporary passive replication blocks at replication origins. Our results do not exclude the possibility that interactions between Mcm10 and MCM2-7 may persist beyond the initiation step into the elongation phase. Further studies will inform other roles that Mcm10 might play in DNA replication.

\section{Materials and methods}

Strains and plasmids

Plasmids and strains used in this study are listed in Table 2. Yeast transformation was performed using the lithium acetate method (Ito et al. 1983). The Escherichia coli strain used for routine cloning was $\mathrm{DH} 5 \alpha$.

Isogenic ori1 mcm10-1 strains were constructed as follows: a $\Delta$ trp1 Dori1 strain (YK15, a his3 his4 leu2 ura3 mom10-1 $\Delta \operatorname{trp} 1 \Delta$ ori1::URA3) was first constructed by disrupting the TRP1 ORI1 locus with URA3 in the mcm10-2c strain (Merchant et al. 1997). Various ori1 alleles were constructed by replacing the disrupted ori1 locus with the TRP1-ARS1 fragments isolated from pTA1 (for mcm10-1 ORI1), pARS1/865-872 (for mcm10-1 ori1-a), pTA1/756-758, 798-805 (for mcm10-1 ori1b2b3), pTA1/835-842 (for mcm10-1 ori1-b1) or pTA1/756-758 (for mcm10-1 ori1-b3), respectively.

\section{Chromatin immunoprecipitation}

Formaldehyde cross-linking and immunoprecipitation were carried out as described (Aparicio et al. 1997; Tanaka et al. 1997). The strain (a bar1 ade2 can1 his3 trp1 leu2 $\triangle$ mom10::MCM10$9 M Y C)$ was constructed as follows: an amino terminus truncated MCM10 gene was cloned in pRS406. A 9× Myc epitope cassette (a gift from K. Nasmyth, IMP-Research Institute of Molecular Pathology, Vienna, Austria) was inserted at the 3' end of the gene as a NotI fragment. The plasmid was then linearized by NcoI digestion and integrated at the MCM10 locus of W303bar1. The primers used for the amplification of ORI1 and the 240-bp sequence were 5'-GAAATAGGTTATTACTGAGTAG/ $5^{\prime}$ CCTGCGATGTATATTTTCCTG and 5'-CATCAATTGTGCACTCGGAC/5'-GAACACGGCAATTGTAGGTGG, respectively. The condition for PCR was $1 \times\left(2 \mathrm{~min}\right.$ at $95^{\circ} \mathrm{C}, 3 \mathrm{sec}$ at $55^{\circ} \mathrm{C}, 6 \mathrm{sec}$ at $\left.72^{\circ} \mathrm{C}\right) ; 28 \times\left(30 \mathrm{sec}\right.$ at $95^{\circ} \mathrm{C}, 30 \mathrm{sec}$ at $55^{\circ} \mathrm{C}, 60 \mathrm{sec}$ at $\left.72^{\circ} \mathrm{C}\right) ; 1 \times 4 \mathrm{~min}$ at $72^{\circ} \mathrm{C}$. PCR products were separated in a $6 \%$ PAG and visualized with ethidium bromide.

\section{Plasmid stability assays}

Yeast minichromosomes were transformed into yeast using the lithium acetate method (Ito et al. 1983). Transformants were plated onto YEPD, and grown for 11-16 generations until individual colonies were visible. Individual colonies were resuspended in total, and plated on both complete and selective plates after appropriate dilutions. The total numbers of cells in each colony that grew on complete and selective media were determined and plasmid loss rates were calculated. Loss rates per cell per generation were calculated using the equation 
Homesley et al.

Table 2. Plasmids and strains

\begin{tabular}{|c|c|c|}
\hline Strain & Genotype & Source \\
\hline W303bar1 & $\boldsymbol{a}$ bar1 ade2 can1 his3 trp1 ura3 leu2 & Y. Kawasaki (unpubl.) \\
\hline $8534-\mathrm{M} 2$ & a leu2-3,112 ura3-52 his $4 \Delta 34$ mcm2-1 & Yan et al. (1993) \\
\hline $\mathrm{R} 61-3 \mathrm{C}$ & a leu2-3,112 ura3-52 his $4 \Delta 34$ mcm3-1 & Gibson et al. (1990) \\
\hline DBY2035 & $\alpha$ his4-619 ura3-52 mcm4-1(cdc54) & Moir et al. (1982) \\
\hline BY2028 & a ura3-52 ade2-1 lys2-801 leu2-3,112 mcm5-461(cdc46-1) & Moir et al. (1982) \\
\hline 434 & a ade2-1 mcm5-462(cdc46-2) & Moir et al. (1982) \\
\hline 436 & $\boldsymbol{a}$ ade2-1 his4 434 mcm5-463(cdc46-3) & Moir et al. (1982) \\
\hline 437 & $\boldsymbol{a}$ ade2-1 mcm5-465(cdc46-5) & Moir et al. (1982) \\
\hline DBY2029 & $\alpha$ ade2-1 lys2-801 leu2-3,112 ura3-52 mcm7-1(cdc47-1) & Hennessy et al. (1991) \\
\hline DBY2027 & a ade2-1 lys2-801 leu2-3,112 ura3-52 cdc45-1 & Moir et al. (1982) \\
\hline LHY1A & a leu2-3,112 ura3-52 his3 his4 mcm10-1 mcm7-1 & this study \\
\hline LHY5C & a leu2-3,112 ura3-52 ade2-1 mcm10-1 mcm7-1 & this study \\
\hline LHY4B & a leu2-3,112 lys2-801 ura3-52 mcm10-1 mcm5-461 & this study \\
\hline LHYTM18C & $\alpha$ leu2-3,112 cdc47-1 mcm5-461 mcm10-1 & this study \\
\hline BTY103 & a ade2-1 can1-100 his3-11,15 leu2-3,112 trp1-1 ura3-52 mcm10-43 & this study \\
\hline BTY106 & $\boldsymbol{a}$ his4 $\Delta 34$ ura3-52 leu2-3,112 mcm10-43 & this study \\
\hline Plasmids & Description & Source \\
\hline pLitmus28-MCM10 & pLitmus28 with EcoRI/XbaI MCM10 fragment & this study \\
\hline pLitmus28-mcm10-1 & pLitmus 28 with $E c o$ RI/XbaI mcm10-1 fragment & this study \\
\hline pRS315-MCM10 & ARSH4 LEU2 CEN6 MCM10 & this study \\
\hline pRS316-MCM10 & ARSH4 URA3 CEN6 MCM10 & this study \\
\hline pRS316-MCM7 & ARSH4 URA3 CEN6 MCM7 & this study \\
\hline pNKY51 & URA3-hisG cassette for disruption & Alani et al. (1987) \\
\hline pUC119-MCM10 & pUC119 with MCM10 & this study \\
\hline YEp24-MCM10 & $2 \mu$ ori $U R A 3 M C M 10$ & this study \\
\hline YEp24-MCM7 & $2 \mu$ ori $U R A 3 M C M 7$ & this study \\
\hline pGAD-C2-MCM10 & pGAD-C2 with $G A L 4 A D-M C M 10$ fusion & this study \\
\hline pGAD-C2-mcm 10-1 & pGAD-C2 with GAL4AD-mcm10-1 fusion & this study \\
\hline pGBDU-C2-MCM10 & pGBDU-C2 with $G A L 4 B D-M C M 10$ fusion & this study \\
\hline pGBDU-C2-mcm 10-1 & pGBDU-C2 with GAL4BD-mcm10-1 fusion & this study \\
\hline pGAD-C3-MCM7 & pGAD-C3 with GAL4AD-MCM7 fusion & this study \\
\hline pGAD-C3-mem7-1 & pGAD-C3 with GAL4AD-mcm7-1 fusion & this study \\
\hline pGBDU-C3-MCM7 & pGBD-UC3 with $G A L 4 B D-M C M 7$ fusion & this study \\
\hline pGBDU-C3-mcm7-1 & pGBD-UC3 with GAL4BD-mcm7-1 fusion & this study \\
\hline
\end{tabular}

$1-(F / I)^{1 / N}$, where $I$ is the total number of cells (those growing on complete media) after $N$ generations, and $F$ is the number of cells that retain the plasmid (those growing on selective media) after $N$ generations. All loss rates were the average of at least three data points.

\section{Two-dimensional DNA gel electrophoresis}

Two-dimensional DNA gel electophoresis was performed according to the neutral-neutral method (Brewer and Fangman 1987). Purified DNA was digested to completion with NcoI. To enrich the sample for replicating DNA, digested DNA was passed through BND cellulose (Sigma, St. Louis, MO) columns as described in (Dijkwel et al. 1991). ORI1 probes were made by isolating the $4.7-\mathrm{kb} N \mathrm{NcOI}$ fragment of ORI1 and radiolabeling using random hexameric primers (Pharmacia, Uppsala, Sweden). Radioactive probe at $2.5 \times 10^{7} \mathrm{cpm}$ was added to $20 \mathrm{ml}$ of hybridization solution and incubated with the membrane at $42^{\circ} \mathrm{C}$ for $24 \mathrm{hr}$.

Yeast two-hybrid analysis

MCM10 and mcm10-1 genes were amplified by PCR from yeast genomic DNA using primers constructed to contain BglII sites, then cloned into Litmus 28. All inserts were fully sequenced before continuing with the cloning procedure. The genes were then digested from Litmus 28 with BgIII and cloned into pGADC2 and pGBDU-C2 (James et al. 1996) at the BglII site. The 5' ends of MCM7 and mcm7-1 were amplified from plasmid DNA using BgIII/SmaI-containing primers and cloned into the SmaI/ BglII sites in pGAD-C3 and pGBDU-C3. The $3^{\prime}$ end of the gene was ligated into the resulting plasmid by cloning a $\mathrm{BgIII} / \mathrm{BamHI}$ fragment into the BgIII site. All of the resulting plasmids were checked for complementation of temperature-sensitive mutants. Wild-type genes complemented the temperature-sensitive mutants, whereas mutant genes did not. Plasmids were transformed into PJ69-4a (James et al. 1996) and selected for on complete media lacking leucine and uracil. Colonies were then assayed for $\beta$-galactosidase activity in liquid cultures as previously described (Ausubel et al. 1998). At least three colonies (two dilutions each) were tested for each plasmid combination and an average taken.

\section{Sequencing of the two mcm10 mutant alleles}

The approximate locations of the $m c m 10$ mutations were first mapped using gapped plasmid repair (Sambrook et al. 1987) and then the exact locations were determined by PCR sequencing. 
Genomic PCR of the MCM10 gene was performed in both mcm10-1 and mcm10-43 (dna43-1) strains using the following primers: 5 '-TCGTGAATTCATGAATGATCCTCGTGAA-3' (5' end of gene), and 5'-ACACGTCGACTTATTTATATTATCTCAAGATC ( $3^{\prime}$ end of gene). Sequencing of at least two independent PCR products for each strain was performed, and mutations were confirmed by sequencing of both Watson and Crick strands, using primers complementary to both 3 ' end and $5^{\prime}$ end of the gene as well as internal gene sequence.

\section{Acknowledgments}

We thank Tamara Petroff for construction of the isogenic mcm10-1 and mcm10-43 strains and Weihang Chai for homology searches. We thank Eric Alani, Tim Huffaker, and Paula Traktman for critical reading of the manuscript. Y.K. was a fellow of the Human Frontier Science Program. L.H. and S.S. were supported by the NIH BMCB and G\&D predoctoral training grants, respectively. M.L. was supported by American Cancer Society Grant IRG-86-004-14 and by the Cancer Center and the Research Affairs Committee of the Medical College of Wisconsin. This work is supported by NIH grant GM34190.

The publication costs of this article were defrayed in part by payment of page charges. This article must therefore be hereby marked "advertisement" in accordance with 18 USC section 1734 solely to indicate this fact.

\section{References}

Alani, E., L. Cao, and N. Kleckner. 1987. A method for gene disruption that allows repeated use of URA3 selection in the construction of multiply disrupted yeast strains. Genetics 116: $541-545$.

Aparicio, O.M., D.M. Weinstein, and S.P. Bell. 1997. Components and dynamics of DNA replication complexes in S. cerevisiae: Redistribution of MCM proteins and Cdc45p during S phase. Cell 91: 59-69.

Ausubel, F.M., T. Brent, R.E. Kingston, D.D. Moore, J.G. Seidman, J.A. Smith, and K. Struhl. 1998. Current protocols in molecular biology. John Wiley \& Sons, Harvard, MA.

Aves, S., N. Tongue, and A.J. Foster. 1998. The essential Schizosaccharomyces pombe cdc23 DNA replication gene shares structural and functional homology with the Saccharomyces cerevisiae DNA43 (MCM10) gene. Curr. Genet. 34: 164171.

Bell, S. and B. Stillman. 1992. ATP-dependent recognition of eukaryotic origins of DNA replication by a multiprotein complex. Nature 357: 128-134.

Bell, S., R. Kobayashi, and B. Stillman. 1993. Yeast origin recognition complex functions in transcription silencing and DNA replication. Science 262: 1844-1849.

Brewer, B.J. and W.L. Fangman. 1987. The localization of replication origins on ARS plasmids in S. cerevisiae. Cell 51: 463-471.

Chong, J.P., P. Thommes, and J.J. Blow. 1995. The role of MCM/ $\mathrm{P} 1$ proteins in the licensing of DNA replication. Trends Biochem. Sci. 21: 102-106.

Chong, J., M.K. Hayashi, M.N. Simon, R.-M. Xu, and B. Stillman. 2000. A double hexamer Archaeal Minichromosome Maintenance protein in an ATP-dependent DNA helicase. Proc. Natl. Acad. Sci. 97: 1530-1535.

Coleman, T.R., P.B. Carpenter, and W.G. Dunphy. 1996. The Xenopus Cdc6 protein is essential for the initiation of a single round of DNA replication in cell-free extracts. Cell 87: 53-63.

Dalton, S. and B. Hopwood. 1997. Characterization of Cdc47p- minichromosome maintenance complexes in Saccharomyces cerevisiae: Identification of Cdc45p as a subunit. Mol. Cell. Biol. 17: 5867-5887.

Diffley, J.F.X. 1996. Once and only once upon a time: Specifying and regulating origins of DNA replication in eukaryotic cells. Genes \& Dev. 10: 2819-2830.

Dijkwel, P.A., J.P. Vaughn, and J.L. Hamlin. 1991. Mapping of replication initiation sites in mammalian genomes by twodimensional gel analysis: Stabilization and enrichment of replication intermediates by isolation on the nuclear matrix. Mol. Cell. Biol. 11: 3850-3859.

Donovan, S., J. Harwood, L.S. Drury, and J.F.X. Diffley. 1997. Cdc6p-dependent loading of Mcm proteins onto pre-replicative chromatin in budding yeast. Proc. Natl. Acad. Sci. 94: 5611-5616.

Foss, M., F.J. McNally, P. Larurenson, and J. Rine. 1993. Origin recognition complex (ORC) in transcriptional silencing and DNA replication in S. cerevisiae. Science 262: 1838-1844.

Gibson, S.I., R.T. Surosky, and B.K. Tye. 1990. The phenotype of the minichromosome mutant $\mathrm{mcm} 3$ is characteristic of mutants defective in DNA replication. Mol. Cell. Biol. 10: $5707-5720$.

Hennessy, K.M., A. Lee, E. Chen, and D. Botstein. 1991. A group of interacting yeast DNA replication genes. Genes \& Dev. 5: 958-969.

Hopwood, B. and S. Dalton. 1996. Cdc45 assembles into a complex with Cdc46p/Mcm5p, is required for minichromosome maintenance, and is essential for chromosomal DNA replication. Proc. Nat1. Acad. Sci. 93: 12309-12314.

Ito, H., Y. Fukuda, K. Murata, and A. Kimura. 1983. Transformation of intact yeast cells treated with alkali cations. $J$. Bacteriol. 153: 163-168.

James, P., J. Halladay, and E. Craig. 1996. Genomic libraries and a host strain designed for highly efficient two-hybrid selection in yeast. Genetics 144: 1425-1436.

Kearsey, S.E., D. Maiorano, E.C. Holmes, and I. Todorov. 1995. The role of MCM proteins in the control of genome duplication. Bioessays 18: 183-189.

Kelman, Z., J.-K. Lee, and J. Hurwitz. 1999. The single minichromosome maintenance protein of Methanobacterium thermoautotrophicum $\Delta \mathrm{H}$ contains DNA helicase activity. Proc. Natl. Acad. Sci. 96: 14783-14788.

Lei, M., Y. Kawasaki, M.R. Young, M. Kihara, A. Sugino, and B.K. Tye. 1997. Mcm2 is a target of regulation by Cdc7-Dbf4 during the initiation of DNA synthesis. Genes \& Dev. 11: 3365-3374.

Liang, C. and B. Stillman. 1997. Persistent initiation of DNA replication and chromatin-bound MCM proteins during the cell cycle in cdc6 mutants. Genes \& Dev. 11:3375-3386.

Liang, C., M. Weinreich, and B. Stillman. 1995. ORC and Cdc6p interact and determine the frequency of initiation of DNA replication in the genome. Cell 81: 667-676.

Maine, G.T., P. Sinha, and B.-K. Tye. 1984. Mutants of S. cerevisiae defective in the maintenance of minichromosomes. Genetics 106: 365-385.

Marahrens, Y. and B. Stillman. 1992. A yeast chromosomal origin of DNA replication defined by multiple functional elements. Science 255: 817-822.

Merchant, A.M., Y. Kawasaki, Y. Chen, M. Lei, and B.K. Tye. 1997. A lesion in the DNA replication initiation factor $\mathrm{Mcm} 10$ induces pausing of elongation forks through chromosomal replication origins in S. cerevisiae. Mol. Cell. Biol. 17: 3261-3271.

Moir, D. and D. Botstein. 1982. Determination of the order of gene function in the yeast nuclear division pathway using cs and ts mutants. Genetics 100: 565-577. 
Homesley et al.

Moir, D., S.E. Stewart, B.C. Osmond, and D. Botstein. 1982. Cold-sensitive cell division-cycle mutants of yeast: Properties and pseudoreversion studies. Genetics 100: 547-564.

Owens, J.C., C.S. Detweiler, and J.J. Li. 1997. CDC45 is required in conjunction with $\mathrm{CDC} 7 / \mathrm{DBF} 4$ to trigger the initiation of DNA replication. Proc. Nat1. Acad. Sci. 94: 12521-12526.

Sambrook, J., E.F. Fritsch, and T. Maniatis. 1987. Molecular cloning: A laboratory manual, 2nd ed. Cold Spring Harbor Laboratory, Cold Spring Harbor, NY.

Santocanale, C. and J.F.X. Diffley. 1996. ORC- and Cdc6-dependent complexes at active and inactive chromosomal replication origins in Saccharomyces cerevisiae. EMBO J. 15: 66716679.

Solomon, N.A., M.B. Wright, S. Chang, A.M. Buckley, L.B. Dumas, and R.F. Gaber. 1992. Genetic and molecular analysis of DNA43 and DNA52: Two new cell-cycle genes in Saccharomyces cerevisiae. Yeast 8: 273-289.

Tanaka, T. and K. Nasmyth. 1998. Association of RPA with chromosomal replication origins requires an $\mathrm{Mcm}$ protein, and is regulated by Rad53, and cyclin- and Dbf4-dependent kinases. EMBO J. 17: 5182-5191.

Tanaka, T., D. Knapp, and K. Nasmyth. 1997. Loading of an $\mathrm{Mcm}$ protein onto DNA replication origins is regulated by Cdc6p and CDKs. Cell 90: 649-660.

Tye, B.K. 1999. MCM proteins in DNA replication. Annu. Rev. Biochem. 68: 649-686.

Yan, H., S. Gibson, and B.K. Tye. 1991. Mcm2 and Mcm3, two proteins important for ARS activity, are related in structure and function. Genes \& Dev. 5: 944-957.

Yan, H., A.M. Merchant, and B.K. Tye. 1993. Cell cycle-regulated nuclear localization of MCM2 and MCM3, which are required for the initiation of DNA synthesis at chromosomal replication origins in yeast. Genes \& Dev. 7: 2149-2160.

You, Z., Y. Komamura, and Y. Ishimi. 1999. Biochemical analysis of the intrinsic Mcm4-Mcm6-Mcm7 DNA helicase activity. Mol. Cell. Biol. 19: 8003-8015.

Young, M. and B.K. Tye. 1997. Mcm2 and Mcm3 are constitutive nuclear proteins which exhibit distinct isoforms and bind chromatin during specific cell cycle stages of $S$. cerevisiae. Mol. Biol. Cell 8: 1587-1601.

Zou, L. and B. Stillman. 1998. Formation of a preinitiation complex by S-phase CDK-dependent loading of Cdc45p onto chromatin. Science 280: 593-596.

Zou, L., J. Mitchell, and B. Stillman. 1997. CDC45, a novel yeast gene that functions with the origin recognition complex and Mcm proteins in initiation of DNA replication. Mol. Cell. Biol. 17: 553-563. 


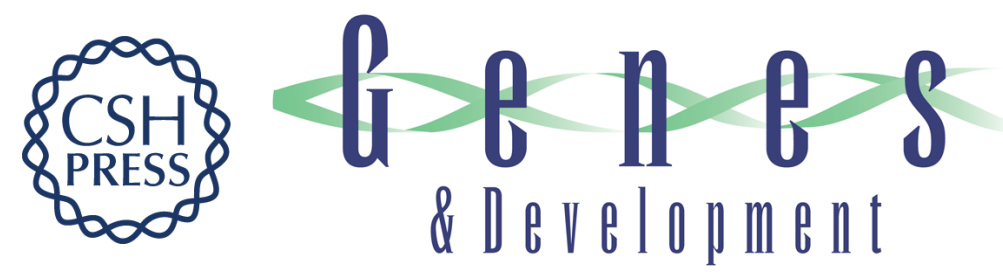

\section{Mcm10 and the MCM2-7 complex interact to initiate DNA synthesis and to release replication factors from origins}

Lisa Homesley, Ming Lei, Yasuo Kawasaki, et al.

Genes Dev. 2000, 14:

Access the most recent version at doi:10.1101/gad.14.8.913

$\begin{array}{ll}\text { References } & \text { This article cites } 40 \text { articles, } 29 \text { of which can be accessed free at: } \\ \text { http://genesdev.cshlp.org/content/14/8/913.full.html\#ref-list-1 }\end{array}$

License

Email Alerting Receive free email alerts when new articles cite this article - sign up in the box at the top Service right corner of the article or click here.

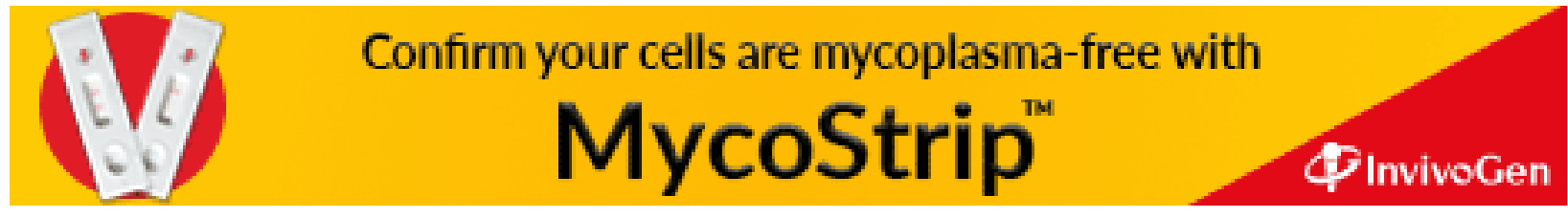

